\title{
Sección Derechos Humanos
}

Convocatoria: Racismos en América Latina. Desafíos actuales

Coordinada por: Claudia Andrea Gotta ${ }^{1}$

\section{Palabras preliminares}

Como producto del proceso de invasión y explotación de los territorios que hoy conforman el continente americano, el sistema colonial creó jerarquías que, basadas en supuestas diferencias biológicas entre los sectores sociales, ubicaron a indígenas y a negros en una posición subalterna. Así, de una vez y para siempre, el colonialismo, convirtió a la raza, en un criterio válido para clasificar a los sujetos en la estructura social. En otras palabras, el orden colonial, fue el orden racial; y de esto dan cuentas las múltiples taxononomías diseñadas y concebidas como derivas del proceso de mestizaje y racialización.

Si bien la matriz modernidad/colonialidad es la que impone una noción de raza, que le es funcional al control de la sociedad y los sistemas de producción implementados, las imágenes prístinas asociadas al racismo -que fueron características en los siglos XVIII y XIX- se fueron modificando con el paso del tiempo, dejando atrás el énfasis en el componente biologicista para referir a un amplio conjunto de ideas o prácticas sociales que segmentan o establecen distinciones entre las personas. De este modo, en los mecanismos de segregación y de exclusión vigentes, el concepto de raza presente en su visión clásica se ha tornado obsoleto, sin por ello dejar de estar vigente en el imaginario social y en el sentido común, adquiriendo nuevas connotaciones.

Hoy en día, el racismo se manifiesta a través de diversos modos de discriminación, al fundamentado en la portación de ciertos rasgos físicos, se suman los basados en lo referente a la estructura clasista, la práctica de creencias religiosas, algunas pertenencias nacionales, determinadas tradiciones culturales, discriminaciones sexistas, etc. Por lo cual, a las desigualdades étnico-raciales, que en su mayoría afectan a las poblaciones indígenas y a afrodescendientes, y de modo más enfático a las mujeres de estos pueblos, se agregan estas nuevas manifestaciones del racismo, lo que nos permite hablar de "racismos" en plural.

Esta nueva realidad, convierte al racismo -en sus diversas manifestaciones- en una práctica capaz de perpetuar la exclusión y la vulneración de los derechos humanos al estructurarse sobre distinciones de diverso signo, a menudo, tan sutiles

\footnotetext{
${ }^{1}$ Docente en Facultad de Humanidades y Artes, Universidad Nacional de Rosario. Historiadora y Educadora Ambiental. Secretaria Nacional de Pueblos Originarios en APDH Argentina. Correo electrónico: gottaclaudiaandrea@gmail.com
} 
y naturalizadas, en el marco de las relaciones de poder instauradas, que son "desapercibidas" y que, en muchas ocasiones, escapan a ser caratuladas como racistas.

En consonancia con todo lo hasta aquí señalado, pensamos este dosier inaugural de la sección de Derechos Humanos, con el convencimiento de que la reflexión sobre los modos de construir diferencias identitarias, y de cómo las mismas fortalecen, y a la vez son retroalimentadas por relaciones de poder colonialistas y racializadas, contribuye a evitar la reproducción de estos esquemas de segregación en nuestras sociedades. Nuestra convocatoria fue abierta, invitando a todes a reflexionar sobre estas expresiones de alteridades otras, geolocalizadas, en el aquí y el ahora, desde el pensar situado de cada une de les autores.

La respuesta a este convite ha resultado de alta satisfacción para nosotres, los artículos recibidos conforman un valioso aporte a la hora de poner en conocimiento y ponderación los racismos presentes en, y desde, América Latina y a la vez nos proponen estrategias posibles para visibilizar los estereotipos en que se los sostienen en pos de su deseada disipación.

Los escritos seleccionados permiten georeferenciar diversas líneas de indagación que persiguen desmontar la invisibilización de las poblaciones afrodescendientes $\mathrm{y} / \mathrm{o}$ indígenas en diversas narrativas que se corresponden a procesos y momentos de la historia latinoamericana y nacional hasta el presente. Entre ellos se encuentra la propuesta de Ángeles Maia Parisio, quien complementa la revisión de los mecanismos que, a través de una matriz eurocéntrica, propiciaron el blanqueamiento racial de la nación argentina con la construcción de categorías raciales que son utilizadas actualmente en el marco de la Ciudad Autónoma de Buenos Aires, para poder finalmente formular algunas reflexiones que emanan de la mirada cotidiana de las y los argentinos.

En la misma sintonía, y como investigadora afrodescendiente, Jessica Nathalie Corpas Figueroa nos propone valorizar las afroepistemologías y los feminismos negros y afrodescendientes, en América Latina y el Caribe, y con mayor especificidad en las contribuciones de Colombia, para poder detectar y analizar en el marco de las ciencias sociales y las denominadas humanidades la restricción/apropiación de estos pensamientos, bajo la categoría de injusticia epistémica.

El trabajo de Alexander Murillo Moreno y el que, en coautoría, nos proporcionan Alejandro Javier Tomás y Hernán Dal Molin, ponen en foco la relación entre racismo, discriminación y subalternización política, para adentrarse en el campo de los derechos negados, en cuanto al reconocimiento y el ejercicio efectivo de los mismos. La relación entre los grupos sociales afectados por esta 
segregación y los Estados es el elemento compartido entre estos dos abordajes, pero el segundo de ellos enfatiza su anclaje empírico en el marco de la nación colombiana.

El artículo de Anaxsuell Fernando Silva centra su análisis en las manifestaciones que encarnan ciertas creencias y prácticas religiosas que, como resultantes de la confluencia de elementos originales y la resignificación de los mismos por la diáspora africana, han configurado un particular escenario religioso, al que califica como dinámico y multiforme, en la región conocida como Tripe Frontera entre Argentina, Paraguay Brasil. El autor nos acerca un análisis de esas prácticas religiosas, emanadas de la presencia afro, ponderando el reconocimiento de las estrategias sociales de marginalización e invisibilización de las mismas, a través de un trabajo de campo de corte claramente etnográfico, en el espacio geográfico seleccionado.

Finalmente, los escritos de Sofía Roizarena y Hamilton Ferreira Dos Santos nos acercan dos problemáticas muy diferentes entre sí pero que confluyen en el magma de los debates de corte político/epistémicos más actuales. El primero de ellos, nos propone analizar algunas narrativas procedentes de los procesos coloniales decimonónicos experimentados por países africanos de mayoría musulmana, para poder visualizar cómo estos relatos racializados operan en, y son resignificados por, diversos movimientos emancipatorios en la actualidad, como el feminismo occidental hegemónico. De este modo Roizarena nos invita a explorar feminismos otros, los cuáles configuran, según la propia autora, otras cartografías posibles de resistencia.

En su trabajo, el brasileño Ferreira Dos Santos, sostiene que el proceso de formación nacional, relacionado con la clase, la raza y el género, es responsable del alto número de vidas que fueron violentamente eliminadas en su país y a la vez vincula de modo sugerente, ese acercamiento histórico al concepto de raza, su formulación "a la brasileña" y el daño históricamente ocasionado a la población negra con los estragos producidos por la actual pandemia de Covid 19 sobre la misma.

Sólo queda ahora invitarles a leer estas contribuciones que nos convocan a repensar nuestras historias y nuestros presentes, al interpelar la matriz modernidad/colonialidad desde uno de sus legados más funestos: el racismo, y junto a ello romper taxonomías que han clasificado arbitrariamente subjetividades, saberes, creencias y sentipensares, desde la concepción monocultural hegemónica.

En definitiva, poder leer/reconocer, a través de estas páginas, cómo el racismo en sus múltiples manifestaciones se nos presenta como uno de los grandes desafíos, al que como sociedad nos enfrentamos. En ese marco, este dossier configura, de modo inaugural, un espacio para poder habilitar narrativas que vuelvan presentes a 
les ausentes, que posibiliten reconocer algunos de los procesos de reproducción y persistencia de las desigualdades sociales y que configuren campos de disputas de sentidos a partir de los cuales podamos repensarnos en este nos/otres que somos.

Claudia A. Gotta

Rosario, ciudad del río marrón, otoño de 2021

\section{Puertas de acceso a la sección}

En esta narrativa de escrituras múltiples y trazos que traen como centro la deconstrucción de los racimos que nos habitan y se han naturalizado en nuestra cotidianeidad negando o disminuyendo la vida humana, les proponemos un texto en clave poética que recupera la figura de mujeres invisibilizadas de nuestra historia reciente, las Madres de los soldados de Malvinas

\section{Cuerpo Soberanía}

Por: Jimena Chaves ${ }^{2}$

Cuerpos, miradas, sentires... se aferran a un devenir incierto...

Arrebatados de casas que todavía esperan...

Cuerpos livianos, castigados, maltratados... pibes... pibes...

Que fueron a una guerra...

Silencio incomodo

Llanto,

Es JULIO, se quebró hablando de su MADRE.

RUBÉN me contó que se aferraba a ella para seguir adelante.

Lo vi en sus ojos, todo se desvanecía cuando recordaban esos momentos.

Dicen que allá murió su juventud, y lo sé, puede sentirlo en sus relatos.

$* * *$

\footnotetext{
${ }^{2}$ Cuerpo Soberanía invita en algunas líneas a pensar y repensar el proceso de indagación que busca el documental "Matria" sobre las madres de Malvinas de la directora Jimena Chaves.
} 
Cuerpos dolidos se detienen en el tiempo, una espera interminable... madres... madres... que sintieron dolor, despojo...

\author{
Crearon \\ Refugios \\ Desde sus propios motivos \\ Y deseos.
}

Desde ahí, ellas renuevan las fuerzas necesarias para abordar la incertidumbre de aquellos días.

$* * *$

Son MUJERES de diferentes provincias de la Argentina cuyas vidas están atravesadas por un doloroso hecho en común: sus hijos fueron enviados a la guerra de Malvinas. El solo acto de decir y el de ser escuchadas, lo que resuena después de tanto tiempo corre el eje de la guerra hasta el fuera de campo y ponen en el centro de la escena los sentires particulares viajando hacia el interior de estas intimidades que se reinventan en un contexto de maternidad-despojo.

Me pregunto...

¿Una madre está preparada para no ver más a su hijo?

Podría yo?

Desde acá pensé y pienso al documental...

Que todavía no se cuenta,

Se supone,

Se piensa,

Se desea...

Este escrito limita el sentir que quiero transmitir, los intercambios de palabras, y los gestos de sus cuerpos trascienden el papel...

Trato de contar algo que no viví, que todavía no hice, que duele.

Pienso...

En soberanía, 
Al CUERPO como soberanía,

Territorio que habitamos.

Me centro en su definición,

La rompo,

Los cuerpos sienten, resuenan.

$* * *$ 